\title{
Development of Single Crystal Filaments Final Report
}

$\begin{array}{cc}\text { Dr. John V. Milewski } & \\ \text { Robert A. Shoultz } & \\ \text { Mary M. Bourque-McConnell } & \\ \text { Superkinetic, Inc. } & \end{array}$

$143195^{\circ}$
$160^{\circ}$

Reference: DOE Project Identification Number DE-FG46-93R699305

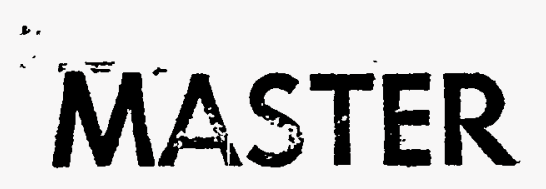




\section{DISCLAIMER}

This report was prepared as an account of work sponsored by an agency of the United States Government. Neither the United States Government nor any agency thereof, nor any of their employees, make any warranty, expresis or implied, or assumes any legal liability or responsibility for the accuracy, completeness, or usefulness of any information, apparatus, product, or process disclosed, or represents that its use would not infringe privately owned rights. Reference herein to any specific commercial product, process, or service by trade name, trademark, manufacturer, or otherwise does not necessarily constitute or imply its endorsement, recommendation, or favoring by the United States Government or any agency thereof. The views and opinions of authors expressed herein do not necessarily state or reflect those of the United States Government or any agency thereof. 


\section{DISCLAIMER}

Portions of this document may be illegible in electronic image products. Images are produced from the best available original document. 
The following summarizes the work performed on the contract to the Department of Energy's Energy-Related Invention Program, titled Single Crystal Whisker Electric Light Filament, referral number 579. The inclusive dates for the contract were August 1, 1993 to February 28, 1995. For a more detailed description of the work performed under this contract see the statement of work and monthly status reports.

\section{Technical Introduction:}

The program just completed addresses a route to a more efficient longer-lasting electric light bulb filament. All current filaments for light bulbs are metallic in nature. They are subject to embrittlement with age ( large grain growth) and relatively high vapor pressures which limits their operating temperature. There is evidence which suggests advantages to using high temperature refractory single crystal fibers as a filament for a light bulb.

These refractory materials may include materials such as hafnium or tantalum carbide which have melting points about $500^{\circ} \mathrm{C}$ higher than tungsten. Another advantage is that single crystal fibers have a very high degree of crystalline perfection with very few voids and dislocations. Without these imperfections, the atomic mobility at high temperatures is highly restricted. Thus single crystal fibers are very stable at high temperature and will last longer.

The efficiencies result from running these single crystal ceramic fiber filaments at higher temperatures and the higher emissivity of the carbide filamentscompared to tungsten. The amount of visible light is proportional to the 4the power of the temperature thus a $500^{\circ} \mathrm{C}$ higher operating temperature will give about a 3 -fold increase in radiation in the visible rang. (see figure 1 ).

\section{Market Summary:}

About $20 \%$ of all power used in the U.S. goes for lighting. A more efficient and longer lasting electric light bulb could be a significant energy and cost saver. Single crystal filaments are very elastic and should last longer. This should be more economical in rugged environments, difficultto-change locations and high radiation environment. Incandescent lighting is more comfortable than the fluorescent lighting and does not have the undesirable flickering, or vibration or hum of the ballast transformers. Creature comfort should be considered. They also work with D.C. current and will better suited for portable and remote applications.

\section{Statement of Work:}

Task 1: $\quad$ Equipment and Hardware Purchase and Assembly.

Superkinetic completed building a diversified and flexible furnace and control assembly suitable for a variety of crystal fiber growth compositions to be evaluated in this program (see figures 2 and 3)

Task 2: $\quad$ Growth of single crystal fiber of sufficient quality Superkinetic grew high quality hafnium carbide ( $\mathrm{HfC}$ ) as long as $8 \mathrm{~mm}$ in length. These lengths were not of suitable length for light bulb filaments experiments. A discussion can be found in the 
Conlcusion and Lessons Learned section of this document.

Task 3 Filament qualifications and analysis

Since the fibers were insufficient for light bulb characterization, only SEM analyses were performed on the fibers generated in task 2 (see figure 4 photograph taken July 1994). The SEMs showed clearly the straight single crystal structure of the fiber and the uniformity of diameters among the different fibers. Uniformity of the fiber diameter along a single crystal fiber and the small variance in the diameter from fiber to fiber is an important parameter in the manufacture of light bulb filaments.

Task 4. Filament mounting Superkinetic completed developing a method for attaching the single crystal fiber to the filament mounting assembly. We found the silver or carbon paste provides good adhesion, thermal transport and electrical conductivity for the testing we performed. Since none of the HfC fibers were suitable for testing, we used mainly silicon carbide fibers for this task .

Task 5. Lamp Assembly

Superkinetic developed special mounting flasks to perform the filament testing (see figure 5). The flasks can be pumped down to a vacuum or flushed through with another gas. The filament mounts fit in the bottom of the flask and sealed with vacuum grease. Power is supplied by a simple power supply which can supply 0 to $120 \mathrm{~V}$ A.C. or D.C.. Voltage and current measurement can be made at the terminals underneath the filament mount.

Task 6. Lamp efficiency Testing Superkinetic performed no efficiency testing however some of the apparatus for performing these tests - power meters and optical pyrometers - were assembled and tested.

Task 7. Manufacturing costs

Superkinetic made no attempt at calculating scaling laws and manufacturing costs since key components in the fiber processing were still being developed at the end of the contract.

\section{Conclusions and Lessons Learned:}

The success of this program was hampered by several unforeseen circumstances. On the technical side, we had problems controlling the chlorine gas flows. It appears our flow controller supplier hadn't sufficient knowledge of the use of their product using such a highly oxidation chemical and problems of O-right swelling and corrosion led to several design changes and a less-thansatisfactory flow control system. Without adequate long-term control, the growth conditions within the furnace varied too greatly to assure the growth of fibers of the right length. Run-to-run variations as a result of this made optimization of the process difficult and time consuming. Unfortunately, the supplier's application engineers were told by their supervisors not to assist us to any great extent (i.e., to replace or flow controllers or help us find the problem). We suspect this non-action was probably taken on account of our company's small size.

Another technical problem was clogging of the furnace apparatus. The original design of the 
input manifold, which was designed for better mixing, would stop-up. The growth conditions would then cease at some point during the run. We tried several different concepts which would resist clogging yet still assure good mixing of the gasses. At the end of the contract, the design which was not implemented would likely of worked since the design just previous worked fine (for the period which good gas control was available).

Programmatically, progress was slow during the period of unexpected funding suspension. Key employee changes and program activity ramping down and up time resulted from the discontinuous funding level.

The program accomplishments can be summarized as follows:

1. Single crystal fibers of $\mathrm{HfC}$ sufficient crystal quality for light bulb filament applications were made.

2. The HfC fiber furnace growth chamber, power control and data collection system was developed for the laboratory scale plant.

3. A method for mounting and apparatuses for testing the single crystal fiber filaments were developed and built.

\title{
Future Plans:
}

Many of the design features of the HfC furnace developed for this program will be used in the short-fiber HfC furnace to make fibers for cutting tools. The primary issues of good gas control and long-term operation in the growth chamber have been resolved. The investigation into the growth of long $\mathrm{HfC}$ fibers will continue as time permits. Long-term growth yielding longer fibers runs are foreseen during the idle periods of the short-fiber cutting tool program. It is important these longer fibers are grown to establish the process and define the single crystal fiber filament product.

Superkinetic also has been participating in ongoing technical discussions with representative from Sylvania and Philips. These companies are providing us insights into the light bulb design and manufacturing issues. These discussions are expected to continue.

Superkinetic's chief engineer will be evaluating long ceramic fibers for light bulb applications as part of his Master's thesis research at the University of New Mexico. He will be studying materials electrical parameters which should determine the suitability of single crystal fibers for light bulb filament usage.

\section{DISCLAIMER}

\begin{abstract}
This report was prepared as an account of work sponsored by an agency of the United States Government. Neither the United States Government nor any agency thereof, nor any of their employees, makes any warranty, express or implied, or assumes any legal liability or responsibility for the accuracy, completeness, or usefulness of any information, apparatus, product, or process disclosed, or represents that its use would not infringe privately owned rights. Reference herein to any specific commercial product, process, or service by trade name, trademark, manufacturer, or otherwise does not necessarily constitute or imply its endorsement, recommendation, or favoring by the United States Government or any agency thereof. The views and opinions of authors expressed herein do not necessarily state or reflect those of the United States Government or any agency thereof.
\end{abstract}




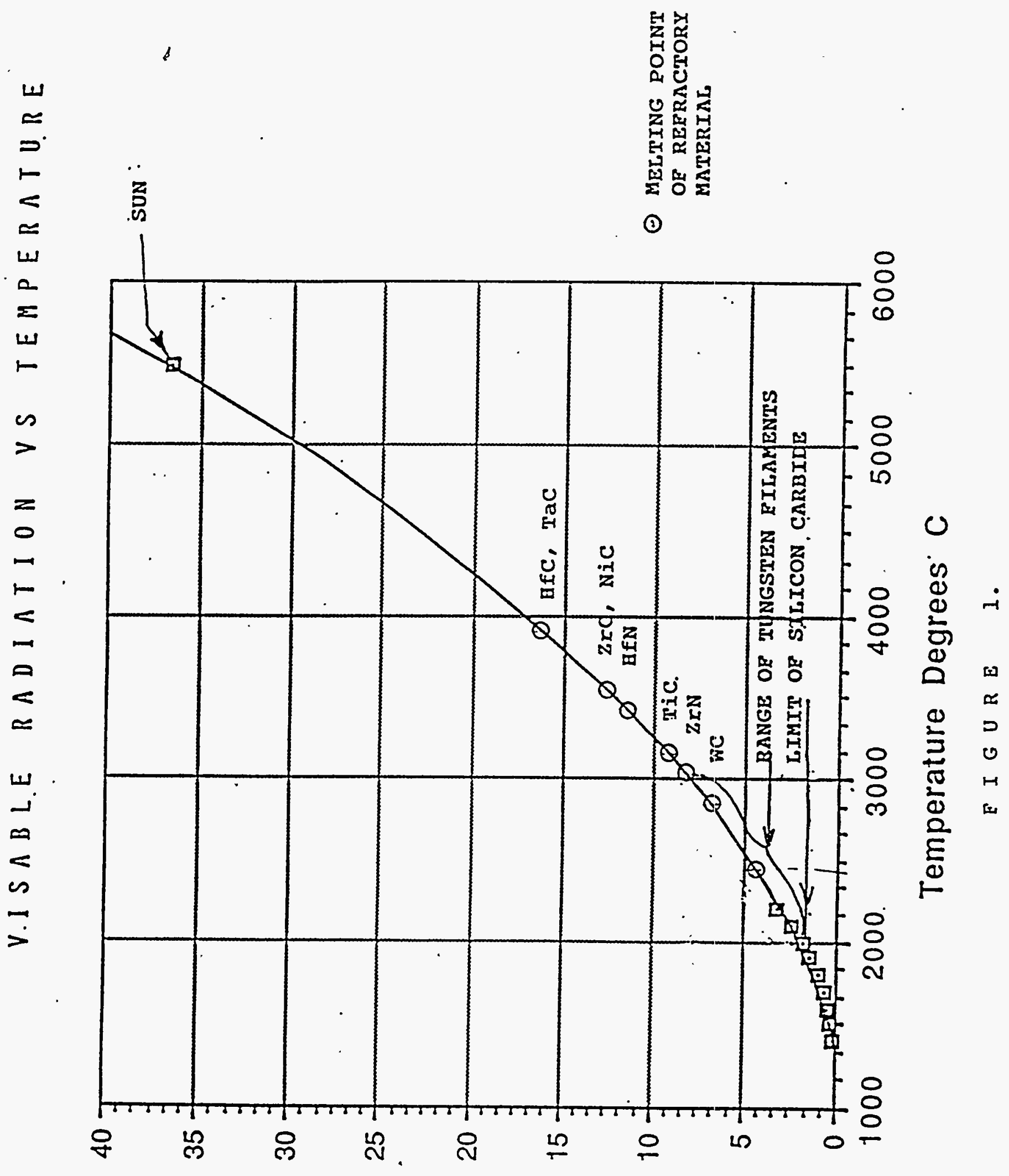

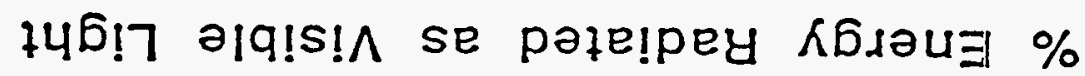

- I $\quad$ a 8 a 0 I 


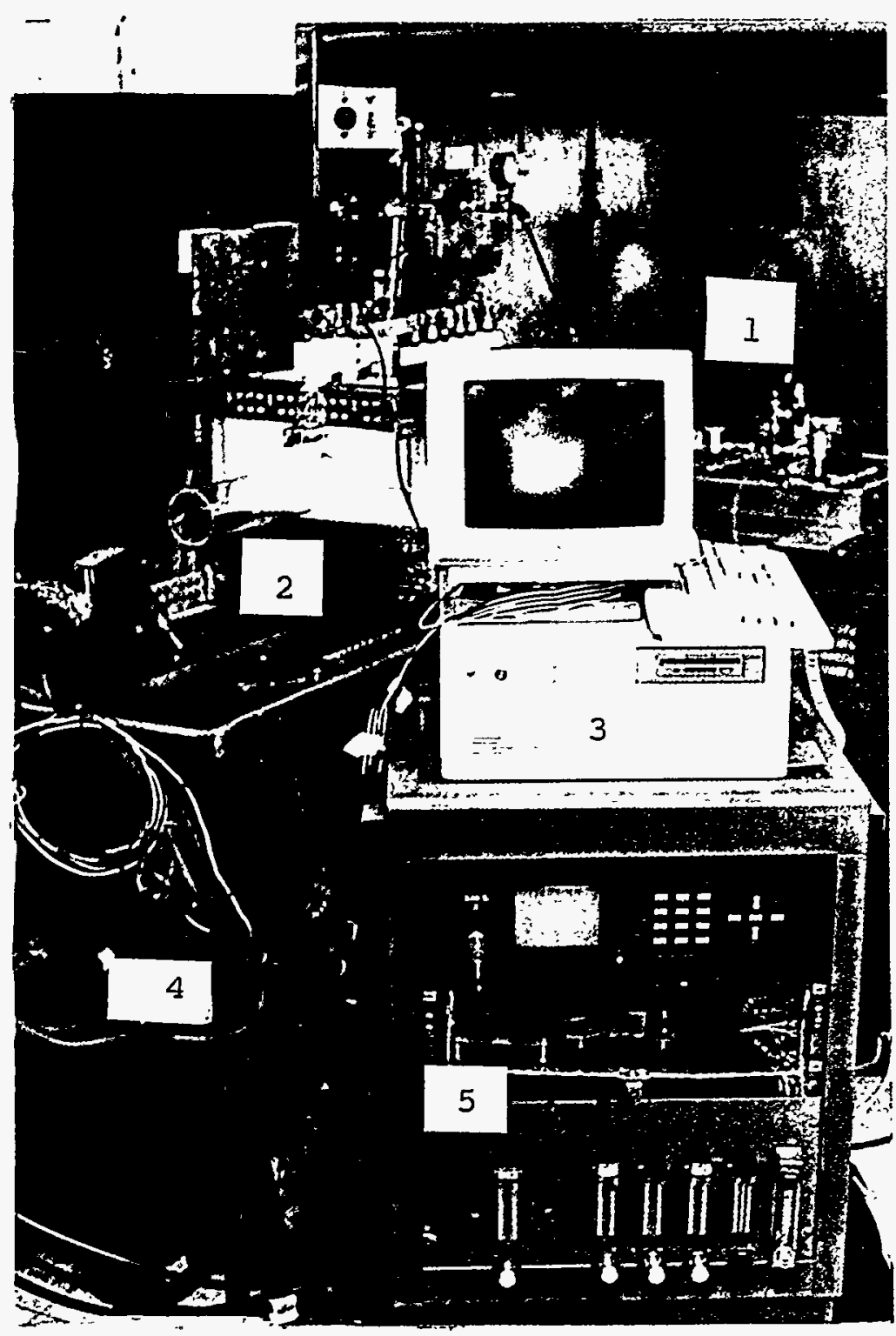

Eigure 2

Over all assembly for HfC Crystal Eiber Growth

\section{MAJOR COMPONENTS}

(1) Chlorine gas flow \& control sub assembly in hood.

(2) Quartz tube furnace assembly with growth reactor inside

(3) Computer to read out data, compile data and integratei and control all sub assemblies

(4) Power supply sub assembly

(5) Gas flow temperature \& safety alarm sub assembly 
CRYSTAL FILAMENMT TESTING ASSEMBLY
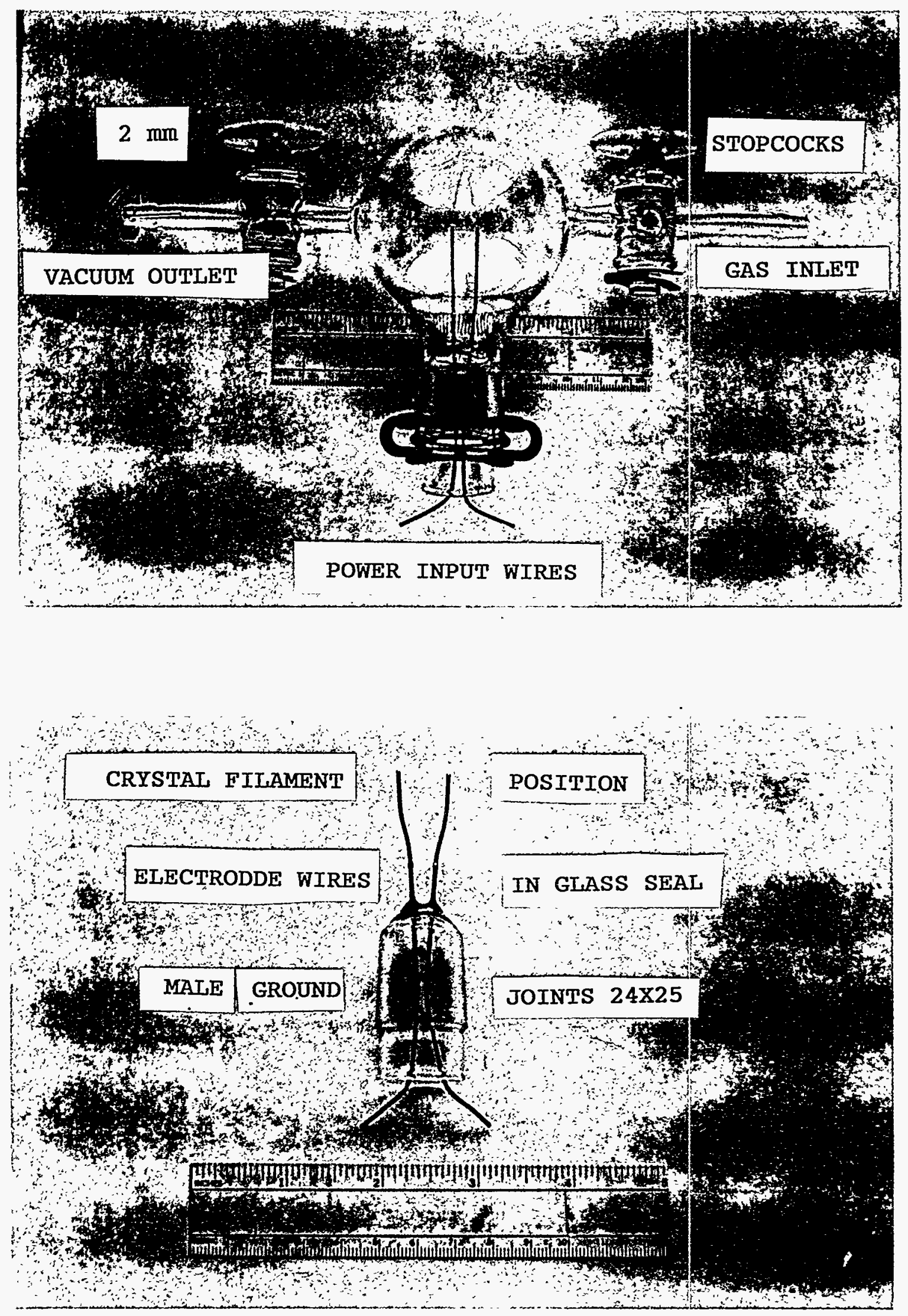

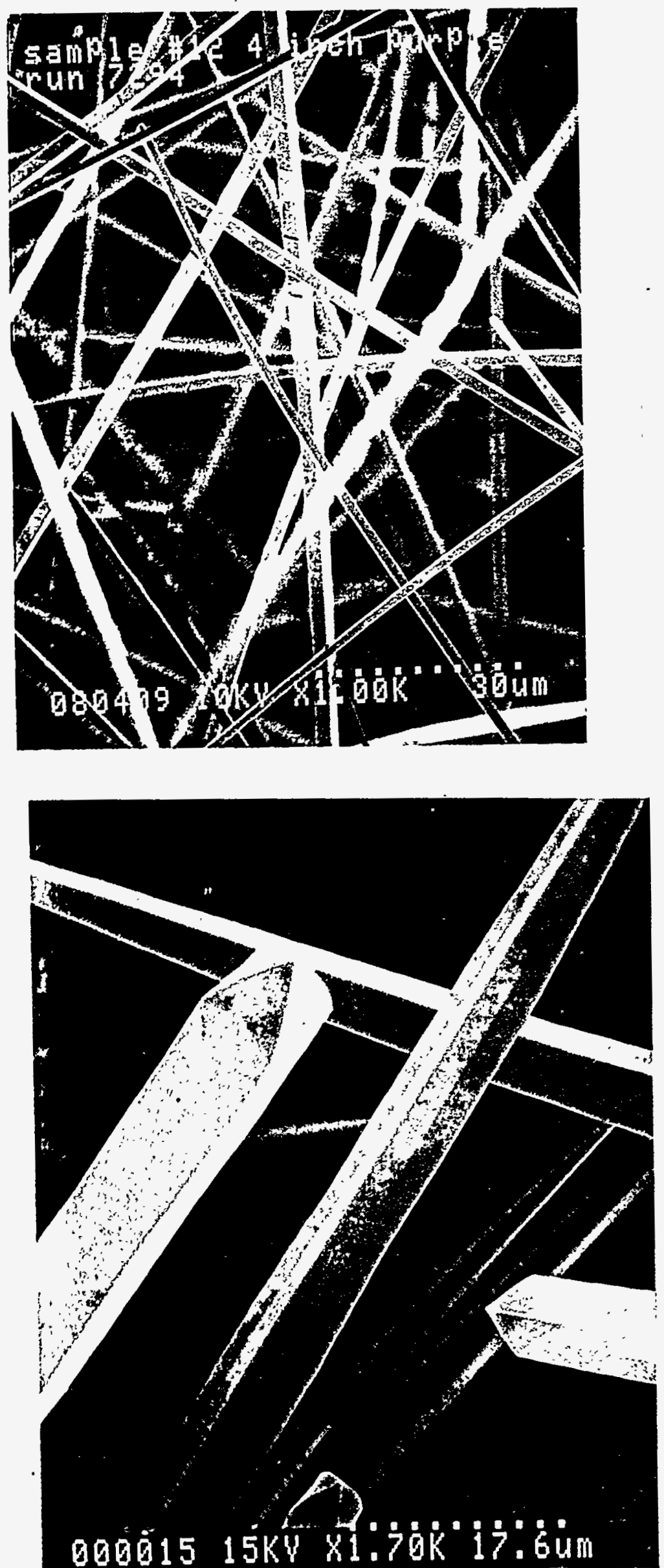

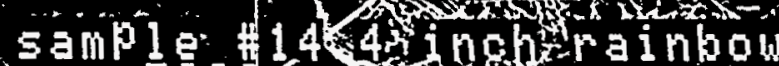
pun 7 gad

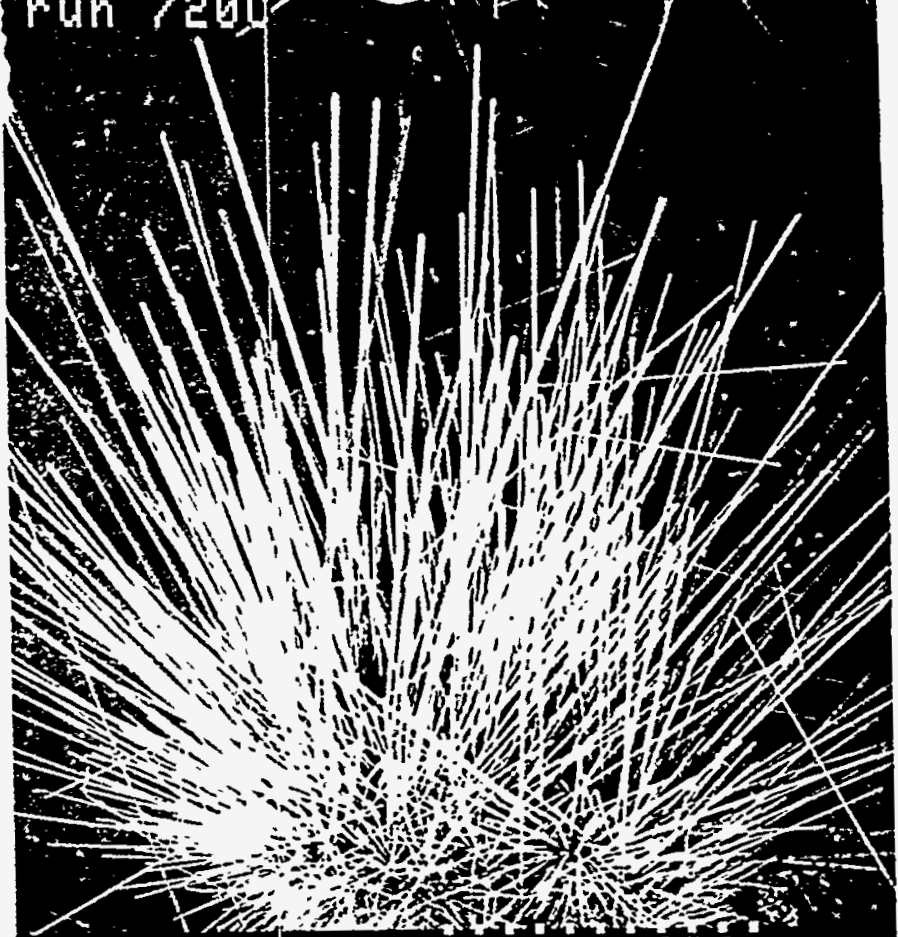

080416 10K4 850.0 6004m

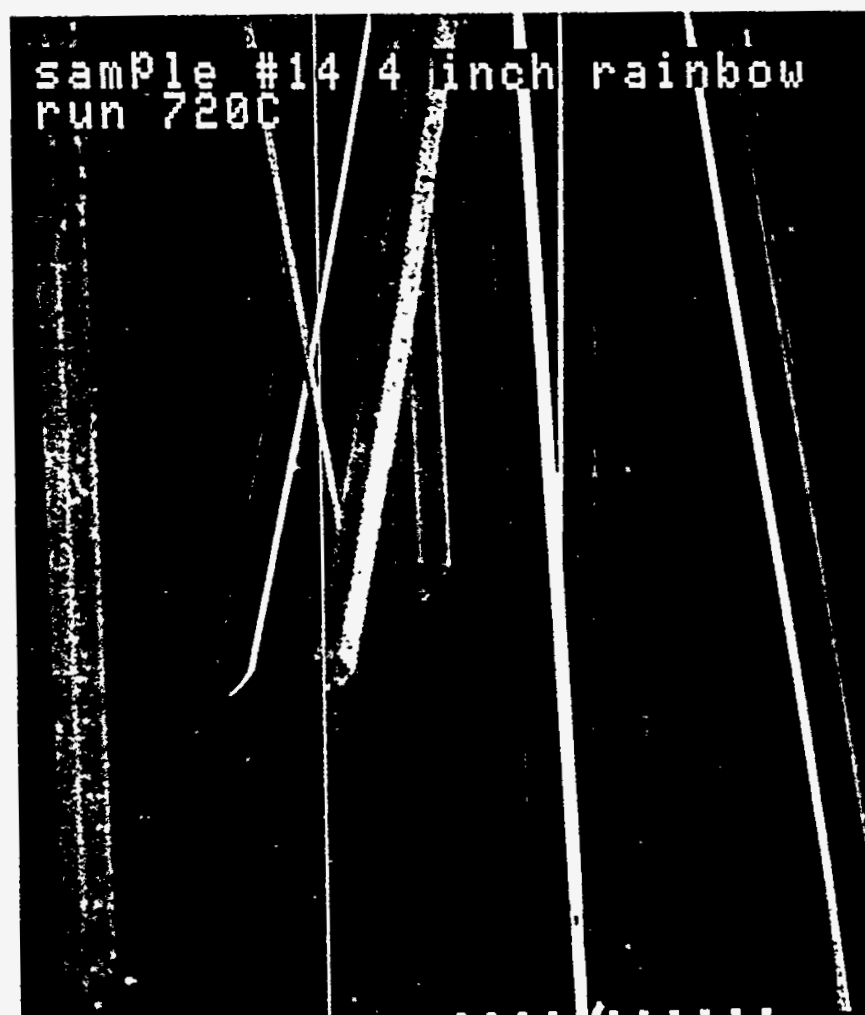

$08041710 k y \quad 8406 \cdot 7540$ 